\title{
INVESTIGATING AND EVALUATING THE INFLUENCE OF SUPPLY CHAIN STRUCTURE ON SUPPLY CHAIN RISK
}

\author{
Z. Sayed ${ }^{1 \#} \&$ B.P. Sunjka ${ }^{1 *}$
}

\section{ARTICLE INFO}

\section{Article details}

Presented at the $27^{\text {th }}$ annual

conference of the Southern African

Institute for Industrial Engineering

(SAIIE), held from 27-29 October 2016

at Stonehenge in Africa, North West,

South Africa

Available online

11 Nov 2016

\section{Contact details}

Corresponding author

bernadette.sunjka@wits.ac.za

\section{Author affiliations}

1 School of Mechanical, Industrial and Aeronautical Engineering University of the Witwatersrand, South Africa

\# The author was enrolled for a BSC Eng (Industrial) degree in the School of Mechanical, Industrial and Aeronautical Engineering, University of the Witwatersrand.

DOI

http://dx.doi.org/10.7166/27-3-1645

\section{ABSTRACT}

Supply chains are exposed to disruptions resulting from internal or external factors that hinder the performance of one or more of their constituent entities. An exploratory study was conducted to determine whether supply chain structure (SCS) influences supply chain risk (SCR), in the context of small and medium enterprises (SMEs) in South Africa. Thematic content analysis was applied to the case data of four Gauteng-based manufacturing SMEs (SMMEs), and summarised in a literature-developed, conceptual structure-risk framework. Results indicate that SCS does influence SCR. Investment in facility infrastructure and supplier relationships appear to be the most influential features. SCS also affects the operational and financial risk of an enterprise. These risks drive the SMEs' strategy and reputation, and consequently drive the corresponding risk dimensions (i.e., strategic and reputation risks). These findings are limited, and should not be generalised to all South African SMEs.

\section{OPSOMMING}

Voorsieningskettings word blootgestel aan ontwrigtings as gevolg van interne of eksterne faktore wat die vertoning van een of meer van hul samestellende entiteite belemmer. ' $n$ Studie is geloods om te bepaal watter voorsieningskettingstruktuur binne die konteks van klein en middelslag ondernemings in Suid-Afrika, die voorsieningsketting risiko beïnvloed. Tematiese inhoudanalise is toegepas tot 'n gevallestudie van vier Gauteng-gebaseerde vervaardigingsondernemings en is opgesom in ' $n$ literatuur ontwikkelde, konsepsuele struktuur-risiko raamwerk. Resultate toon dat voorsieningskettingstruktuur wel die risiko beïnvloed. Belegging in fasiliteit infrastruktuur en verhoudings met verskaffers blyk die grootste invloed te hê. Voorsieningskettingstruktuur beïnvloed ook die operasionele en finansiële risiko van 'n onderneming. Die risiko's bepaal die ondernemings se strategie en reputasie en dus ook die ooreenstemmende risiko dimensies (met ander woorde strategiese en reputasie risiko's). Hierdie bevindinge is beperk in hul toepassing en moet nie veralgemeen word tot alle Suid-Afrikaanse klein en middelslag ondernemings nie.

\section{INTRODUCTION}

Small and medium enterprises (SMEs) are the lifeblood of any economy. In South Africa in particular, they form the economic backbone of the manufacturing sector. SMEs account for about 91 per cent of South Africa's formal enterprise, being a key driver of economic growth, reducing unemployment, and being a skills development platform [1]. The operations of South African small and medium manufacturing enterprises (SMMEs) contribute significantly to the country's employment levels and to competitiveness in the global market.

Supply chain risk management (SCRM) in SMEs is still a growing area of interest for practitioners and academics. South African SMEs face unique risks that must be managed and mitigated to be 
successful. Frameworks to classify and manage SME-risks have been proposed in recent years; however, supply chain structure (SCS) has not been emphasised. It follows that the impact of the SCS must be investigated to understand its contribution to supply chain risk (SCR) [2].

This paper addresses the gap between SCS and SCR in SMEs through exploratory research. The study proceeds to highlight the SCS and SCR literature, which forms the basis of a conceptual risk-structure framework. Case study data (derived from four SMMEs in the steel and engineering sector) in the form of interviews, supply chain maps, and company websites is analysed to identify risk-structure elements and populate the framework. Lastly, the validity and applicability of the developed framework is discussed to highlight its limitations and provide recommendations for future study.

\section{LITERATURE REVIEW}

While no study of the interaction between SCS and SCR has been undertaken in the context of SMEs, several exploratory and explanatory research endeavours have attempted to describe these aspects of supply chain management (SCM). The sections below summarise the SCS and SCR findings, and an overview of the sector under scrutiny is provided to position this exploration in the context of South African SMMEs.

\subsection{Supply chain and risk overview}

\subsubsection{Supply chain structure (SCS) of SMEs}

Supply chains encompass the supply and distribution of materials and information. This includes facilities, locations, and business relationships. Supply chains vary in structure, reflecting the level of collaboration between organisations in the chain [3], [4].

Donald and Waters emphasise that the most important dimensions of SCS include the width and length of the supply chain, the number of facilities, and their locations, functions, operations, and capacities. Logistics arrangements and relationships between each of the organisations are also deemed crucial [5].

A typology of SCS proposed by Stadtler and Kilger [6] classifies SCS into two dimensions: topography, and integration and coordination. Supply chain topography describes the flow of materials and the degree of globalisation, while integration and coordination refers to the power distribution in the chain and the legal position and exchanged information. This model further suggests that the functional characteristics (i.e., procurement, production, distribution, and sales) of each supply chain entity may be linked to structural features.

Lambert et al. [7] describe SCS in terms of a 'members-and-links' network, forming a critical component in SCM. This model decomposes the SCS into three components:

- Supply chain members: These consist of all organisations with which the focal business interacts from the origin to the end of the chain. Members may have a role that is primary (i.e., carrying out operational/managerial activities to produce an output for customers) or secondary (i.e., providing resources, knowledge, or assets to primary members).

- $\quad$ Structural network dimensions: Three structural features are crucial to describing the supply chain. These include the horizontal and vertical structures, together with the horizontal position of the analysed company in the supply chain. The horizontal structure refers to tiers in the chain, while the vertical discusses the number of suppliers and/or customers in each tier (see Figure 1). Lastly, the company under consideration can be located within the endpoints of the supply chain using its horizontal position.

- Supply chain process types: Process links are classified into four distinct types. Managed process links (i.e., between the focal company and its immediate customers or suppliers) and monitored process links (between other companies) are considered crucial to the focal company for SCM and integration - they are monitored and audited by the focal company. In contrast, not-managed process links are those with which the focal organisation is not actively involved, and have no impact to warrant supervision. The final type, non-member process links, refers to the extremities of the chain (i.e., between the focal company's supply chain and nonmembers). These are not classified as part of the chain, but affect the success of the focal company and the supply chain. 


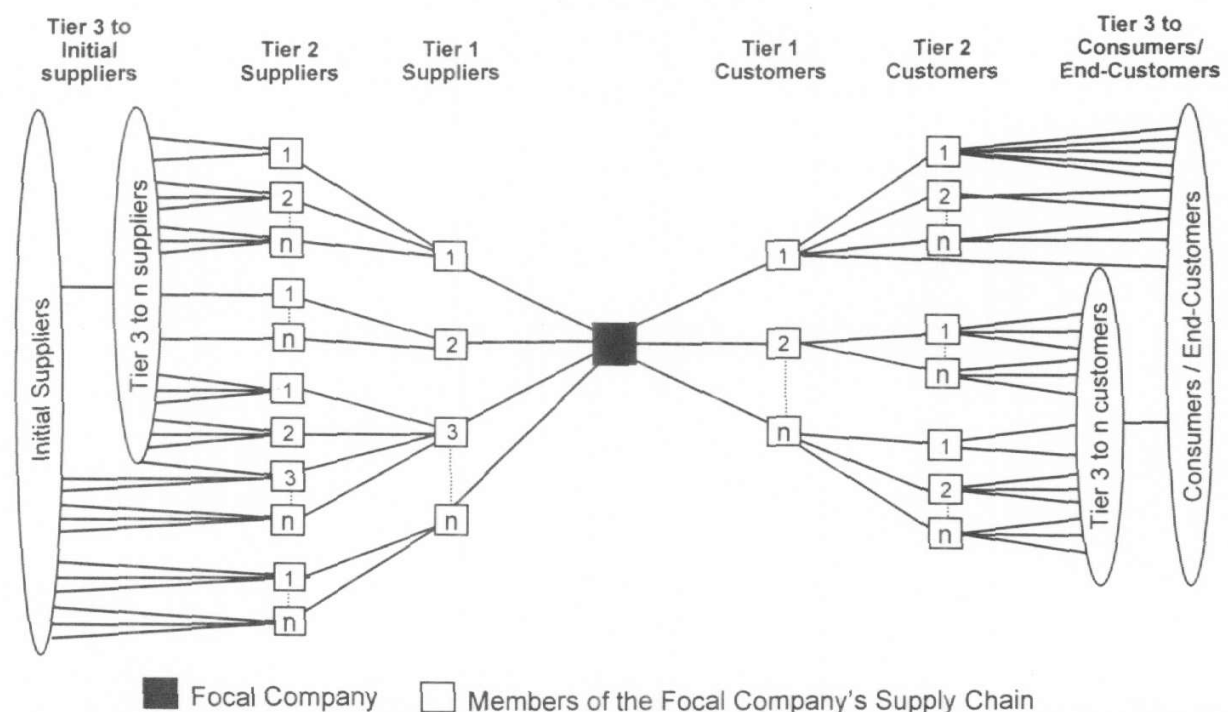

Figure 1: Supply chain network structure [7]

In the same vein, Slack and Lewis [4] adopt a network perspective of the SCS that includes the flow of both materials and information. This view of SCS includes the basic connections and features in the SCS as discussed above (by Lambert et al.), but also highlights how many of the supply chain companies are in direct competition with each other, and yet often collaborate. This results in crossflows between the tiers of the supply chain network.

With the various possible SCS arrangements, it is clear that the organic configurations allow SMEs the opportunity to flourish (owing to adaptability and agility in the supply chain) [8], but also have a significant impact on the ability of the SME to plan effectively [9]. To cope with these impacts, research suggests that SMEs use the type of customer experience they wish to provide as a guide to developing their SCS. It is also important to take cognisance of the advantages and disadvantages of each structure, depending on the type of customer served [10].

It is thus crucial for (large and small) companies to be conscious of the dynamic nature of a SCS. Often, the network cannot remain fixed if it hopes to survive changes (e.g., market forces, political and social change, enterprise growth, or downscaling) that impact the business. Wickham (as described by Nieman and Nieuwenhuizen [11]) highlights the importance of internal structural modification over the venture life cycle (VLC) of the focal company. Companies must develop and modify their structure to satisfy change and growth demands. Modifications must address the size, organisational technology, strategy, and environmental features of the focal organisation. These changes will then have implications for SCR, SCM, and operations within the chain. The altered network may have positive, negative, or a combination of effects on the focal company and the chain [10].

The literature also highlights that poor organisational structure limits the implementation of SCM, with Day (as described by Dubihlela [12]) advising SMEs to formulate supply chain objectives within the business' objectives. The effects of risk on the shape of the supply chain must also be considered in the planning and operations of the business [13].

While little insight into SCS has been uncovered with respect to SMEs, it is clear that linear supply chain models are unsustainable in the marketplace. Thus amorphous SCSs would be dominant, having the ability to respond and adapt accordingly to changes in the market.

\subsubsection{SME risk classification}

Globalisation has introduced increased specialisation and a need for low-cost communications and complex logistics [3]. This phenomenon has resulted in companies producing fewer goods, opting instead to purchase [3], [4]. Both large enterprises (LEs), and SMEs now place more reliance on 
supply chains, thus increasing risk. Heizer and Render [3] hold that the use of fewer suppliers increases customer-supplier dependancy, which contributes to increased risk for both parties.

In the context of LEs and SMEs, risk is a multidimensional concept that refers to loss (including financial, performance, physical, physiological, social, or time), which may stem from various sources [14]. These sources are often classified into internal or external factors - i.e., within the organisation, or beyond the company's control. SMEs and LEs differ, however, in experiencing the extent of the various SCRs. SMEs share common (micro-economic) traits - i.e., a lack of resources, constrained information technology (IT) infrastructure, organic business processes, a lack of capital, and low access to economies of scale [14], [15]. Thus establishing a comprehensive risk profile for an SME is a challenge.

South African SMEs in particular face numerous risks that pose a significant threat to the survival of the businesses. In addition to the above-mentioned challenges, the South African SME also experiences crime, low productivity (which includes the challenges of access to electricity and technology, cultural communication barriers, and the lack of skilled labour), difficult access to markets, finance, and credit, the need to develop customer relationships and reputation, and sourcing knowledge and government support [1], [10], [14]. These risks are often referred to as macro-economic factors, indicating that they are beyond the control of the company.

Several models have been developed in an attempt to include the multiple dimensions of risk in the SME supply chain. ZandHessami and Savoji [13] highlight and explain seven key risks:

- Financial risk: relates to the inability of an organisation to meet financial obligations.

- Strategic risk: includes present and future profit, which is subject to strategic goals.

- Operational risk: risks arising from methods employed to conduct and monitor the business' operations - e.g., production processes, use of equipment, etc.

- Human resources risk: risk of a lack of personnel who are adequately trained/skilled to promote to management, or who are incapable of dealing intelligently with 'unexpected accidents'.

- Technological risk: risk stemming from information systems (ISs), automation, and the misconception of the role of technology in the enterprise.

- Reputation risk: describes both the current and future risk of an organisation's ability to earn or increase capital from different financial firms and commercial beneficiaries.

- $\quad$ Laws risk: relates to adherence to laws in business operations and management.

Attempts to define a broader risk classification have also been carried out. Mason-Jones and Towill [14] propose five overlapping dimensions: environmental (external), supply, demand, process, and control risks (referring to the design and implementation of processes). Whichever classification is employed, risk must be actively managed and monitored to ensure the survival of the enterprise.

\subsubsection{Supply chain risk management (SCRM) for SMEs}

SCRM is considered to be a relatively new research area in the field of SCM, and so is deficient in the context of SMEs [16] owing to the lack of knowledge about small businesses. However, it has been established that risk management practices are often integrated into the operational management of SMEs [16].

The literature indicates the importance of SCRM in protecting LE or SME resources against supplychain-collapse. It is suggested that SMEs introduce and embed a structured risk management approach, allowing their mission and objectives to be achieved [16], [11].

The process of risk management has five steps: identification, evaluation, management methods selection, implementation, and regular review to control risk [11]. Heizer and Render [3] suggest that risk management be carried out in three areas of the business: processes (material availability, quality, and logistics), controls (management metrics, secure communication strategy, and logistics scheduling), and the environment (monitoring macro-economic factors).

Nieman and Nieuwenhuizen [11] describe four possible strategies for SMEs to consider in managing risk, as outlined below. It is important to note that each strategy is not always applicable, and is subject to change depending on the circumstances of the business. 
- $\quad$ Retention: bear the risk and accept it as part of the business.

- $\quad$ Reduction: revise the business plan to accommodate and implement management control and safety programmes.

- Avoidance: avoid investment in new business ventures, and avoid doing anything at all in the existing business.

- Transfer: limit the ownership of major loss through underwriting and insurance policies.

Whichever strategy is implemented, it is evident that SCRM must occur within the LE or SME. It must be actively managed to ensure the success of the focal organisation and the supply chain as a whole.

\subsection{South African steel and engineering manufacturing industry}

Manufacturing is a core driver of gross domestic product (GDP), and is essential to reducing unemployment and promoting economic growth [17]. South Africa is no exception to this. However, increased globalisation threatens the sector's success.

Steel and engineering (which forms part of the metals and machinery sector) is a dominating enterprise-area, contributing to a large portion of total manufacturing production [18]. However, the steel industry has struggled to be profitable in the last few years, being the largest contributor to weak manufacturing production performance in 2014 [18].

The industry has been characterised as volatile and difficult to compete in. This has been attributed to the global market being infiltrated by cheaper Asian products, crippling industrial action, and a lack of governmental support [19], [18], [20]. Adding to these environmental factors is an unreliable electricity supply and its increasing cost. Electricity is a critical input for metal-related production; so outages and price hikes threaten the survival of the industry [19], [20].

In conclusion, the literature illustrates that no clear correlation between supply chain structural characteristics and SCRs has been established. No framework descriptive of SCS-and-SCR has been located for LEs or SMEs. Thus, drawing from published work, a conceptual framework (in Figure 2) was developed to illustrate the links between structural attributes and risk dimensions. Donald Waters' SCS description [5] and ZandHessami and Savoji's key risk factors [13] were used to this end. Hypothesised links were subsequently established.

\subsection{Hypotheses formulation}

\subsubsection{Location}

Slack and Lewis [4] suggest that location decisions are fundamental to an organisation's investment and operational resources. Numerous factors contribute to location: site suitability, location image, achievable service levels, and a variety of decision-influencing resources. Locations are associated with a certain image in the mind of a customer, affecting an organisation's reputation and its ability to attract customers. From a more measurable perspective, the ability to provide and receive acceptable service is a crucial demand-side factor. It impacts speed and dependability, which are important performance objectives [4]. As mentioned in Section 2.1.1, SMEs should create an SCS in accordance with the customer experience it wishes to provide, identifying and evaluating the benefits and risks associated with these structural choices. Companies might choose to locate close to customers (to gain a competitive advantage) or to suppliers (to ensure fast, dependable supply). Fatoki and Asah (as cited by Gono et al. ) describe geographical proximity to critical buyers or suppliers as being important to an SME's identification and exploitation of market growth opportunities. Location is a driver of both cost and revenue, having the ability to make or break a business strategy [3]. Investment in land and/or infrastructure, labour, transport, energy costs, and their reliability must also be considered. Compounding this is the influence of political, social, and economic aspects that will have implications for both operations and strategy [3]. The above facilityfindings make reference to all the risks faced by South African SMEs (described in Section 2.1.2), suggesting the following hypothesis:

H1: The physical network structure (i.e., facilities and their attributes) will have direct implications for all of the risk dimensions. 


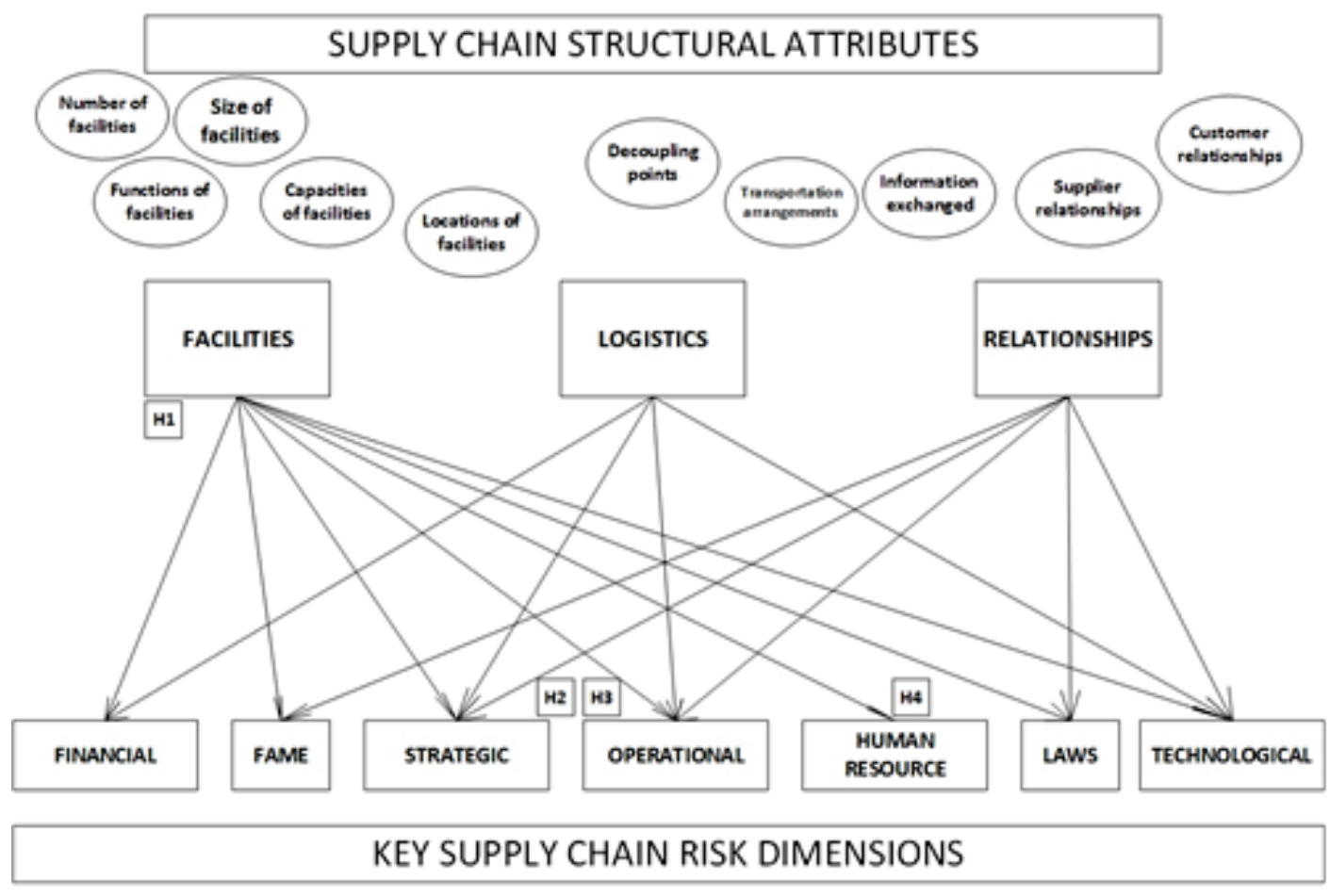

Figure 2: Proposed conceptual framework for SCS and SCR (developed by author)

\subsubsection{Logistics}

Logistics translates market requirements into production requirements (materials, products, and information), making it essential to operations planning. Heizer and Render [3] explain that quickresponse logistics allows supply chains to achieve two strategic goals: cost-reduction and serviceenhancement. Information technology (IT) is identified as a critical enabler, linking points-of-sale to points-of-supply. Companies that integrate logistics into the overall business can successfully achieve cost advantages, holistically assess risk and opportunity across the chain, and develop a focused network-based strategy [3], [4], [21] .

Forbes [22] finds that several companies choose to use low-cost (distant) suppliers rather than local suppliers without fully considering the full cost of the risks associated with this decision. This results in an extended supply chain with new, additional points of potential failure. Meanwhile, Ltd Management [23] asserts that inventory 'velocity' is the key to profitable business - i.e., the faster a product flows through to an end-customer, the more working capital is available to a business. Facilitating this flow means that the supply chain must ensure customers' orders are "shipped complete, accurate and on-time" [23]. Thus it is imperative to ensure a continuous flow of materials and information in the supply chain.

Logistics significantly influences supply chain planning and, therefore, SCM. The literature highlights the close link between logistics performance and its impact on the SME's financial goals. It is expected that logistics would have a strong impact on financial, operations, and strategic risks. Facilities and logistics might also affect each other, reinforcing the effects on SCR.

\subsubsection{Relationships}

Supply chain relationships include buyer-and-supplier relationships and the exchange of information. A pre-condition for effective supply chain planning is information-sharing between companies. Lummus and Vokurka (as described by Hvolby et al. [24]) find that a lack of integration, trust, and tools to indicate alliances are all performance-limiters. Matsoso and Benedict [25] hold that good relationships between the customer and the supplier enhance the delivery of goods and services to the consumer. In the case of SMEs, this relationship is complex owing to the use of several suppliers, leading to "an inability to connect with prominent suppliers, ineffective delivery schedules, and failure to achieve economical prices..." [25]. The benefits of close supplier relationships include easy negotiation of prices and deliveries. This leads to smooth supply chain operations. Long-term 
relationships with a few suppliers might positively impact financial performance if strategically managed. Fostering close supplier-relationships might also allow SMEs to achieve smooth flows of material, economical costs, and timeous delivery [25].

SMEs, however, are often characterised by limited supply chain power and constrained resources for enterprise resource planning (ERP) systems. Effective supply chain planning calls for transparent information-sharing to meet the end-customers' demands. This translates into co-ordination between various entities to satisfy supply chain needs [24].

Adding to the pressure for technological input is the need to service end-customers over the internet. Customers now purchase goods online and demand that small businesses make use of digital service channels, while regulatory and tax authorities call for quick and accurate reporting [10]. Electronic markets are the new channel for conducting business [24]. However, 'e-business' poses a technological risk. The plethora of online threats is a major problem for all businesses, and it is particularly difficult for SMEs to rebuild reputation after an online safety incident [26]. This can be attributed to SMEs' constrained monetary and legal resources. The decision to use digital channels is thus closely related to the current and future profitability of an SME.

The above illustrates the criticality of relationships and information-sharing in SCS. The prominence of digital information - i.e., data-capture systems, online coordination, and sales - suggests that there might be a strong link between relationships (in SCS) and technological risk.

Owing to the recurring theme of supply chain planning and SCM, strategy and operational risks are clearly significant with respect to SCS. This leads to the following two hypotheses:

H2: All SCS facets will have implications for an enterprise's supply chain strategy.

H3: All SCS facets will have implications for an enterprise's supply chain operations.

Finally, the lack of labour-related focus in the supply chain suggests that it may not have strong links with SCS. This leads to the final hypothesis:

H4: SCS has a minimal influence on the human resource risk factor.

\section{3}

\section{METHODOLOGY}

The perusal of the supply chain literature clearly indicates that research into SCR (particularly in respect of SMEs) and SCS is limited. Thus the nature of the present research is exploratory, with the intention of bridging the apparent gaps in this area of supply chain studies.

\subsection{Data acquisition and SME respondents}

This study focused on South African SMMEs operating in industrialised areas in Gauteng. Targeted participants included SME owners/owner-managers of steel and engineering companies. Secondary data was acquired from owner-managers of four SMMEs in the steel and engineering sector. The data included survey responses, transcribed semi-structured interviews, and supply chain maps. Where possible, company websites provided additional information. This approach was suitable to explore multi-dimensional risks, as it drew on various sources that embraced interpretive aspects of a focal firm's internal issues.

In addition to the above aspects, the company cases share the following characteristics:

- The companies are classifiable as a micro-, very small, small, or medium enterprise, using the categories in the National Small Business Act of 1996.

- $\quad$ Each company is regarded as established, with all operating for longer than 10 years.

- The interviewed managers have a personal stake in the company - i.e., the manager is an owner or the SME is a family business.

To maintain the anonymity of the participants, the companies studied for this research will be referred to with pseudonyms. Table 1 summarises the details of the respondents. 
Table 1: Summary of SME respondents

\begin{tabular}{|l|l|l|l|}
\hline \multicolumn{1}{|c|}{ Company } & \multicolumn{1}{|c|}{$\begin{array}{c}\text { Size } \\
\text { classification }\end{array}$} & $\begin{array}{c}\text { Annual } \\
\text { turnover }\end{array}$ & \multicolumn{1}{c|}{ Description of type of work } \\
\hline $\begin{array}{l}\text { SME brakes } \\
\text { manufacturer }\end{array}$ & Medium & $\begin{array}{l}\text { R135-150 } \\
\text { million }\end{array}$ & $\begin{array}{l}\text { Manufacture of braking equipment and pressure } \\
\text { vessels for local and foreign rail and automotive } \\
\text { industries }\end{array}$ \\
\hline SME dye-maker & Medium & $\begin{array}{l}\text { R60-65 } \\
\text { million }\end{array}$ & $\begin{array}{l}\text { High-pressure and gravity dye-casting, supplies light } \\
\text { and electrical-component manufacturers, automotive, } \\
\text { and mining companies }\end{array}$ \\
\hline SME safety \& site & Small & $\begin{array}{l}>\text { R50 } \\
\text { million }\end{array}$ & $\begin{array}{l}\text { Manufacture of fire-safety equipment, construction, } \\
\text { and sundry steel fabrication }\end{array}$ \\
\hline $\begin{array}{l}\text { SME lab \& } \\
\text { catering }\end{array}$ & Medium & $\begin{array}{l}\text { Not } \\
\text { available }\end{array}$ & $\begin{array}{l}\text { Laboratory and related equipment manufactured for } \\
\text { catering, butchery, and welding industries. }\end{array}$ \\
\hline
\end{tabular}

\subsection{Data processing procedure}

An a priori qualitative thematic analysis was applied to the sample SME data. This method includes the encoding of qualitative information in an effort to identify and analyse existing patterns [28], [22]. This top-down approach is useful in directing the researcher's focus to specific dimensions e.g., the structural features and influences of SMEs in supply chains.

Apparent risks were extracted from the raw data and populated into the conceptual framework for each SME. Some SCS features may have a relationship with several risks, compounding their influence on SCR. If there is no entry between a risk and a structural feature, it is because there was insufficient evidence to comment. This encoding was conducted using NVivo, a software package suitable for processing unstructured qualitative data [29].

\section{ANALYSIS AND RESULTS}

The interviews used in this study were conducted in the context of risk management. The available material was not tailored to focus on the structural dimensions. The broader supply chain, the internal organisation, and external factors were discussed. Consequently, dominant themes, apart from those initially defined, emerged.

\subsection{Emergent findings: Risks}

While this study is a priori, risk-influences attributed to the SME environment were prominent and could not be ignored. These aspects have been explained below, and must be considered when analysing structure, as they might influence structure and hence risk.

\subsubsection{Organisational decisions and hierarchy}

The case data shows that organisational hierarchy and communication style influence the SME's structural design in the chain. Respondents who display informal management and do not enforce a hierarchy have good employer-employee relationships. This has positive consequences for the SMEs' market performance and lowers human resource risk. Conversely, a more formal culture results in high human resource and operational risks, particularly during strike seasons in the industry. This exploration thus exposes overarching organisational culture and management, and brings to light the need to adapt management to sustain the SME in the supply chain.

\subsubsection{Quality standards and manufacturing regulations}

Producing poor-quality products because of inadequate processes or design often leads to high production costs and sometimes even to lawsuits. It is necessary that manufacturers deliver safe, quality goods to their customers. This standard, together with other sector and product guidelines, have been mentioned in the SME cases. Owner-managers describe the constraining effects of these standards on customer-dealings, human resources, and actual manufacturing operations. Companies might fail to receive work contracts based on their inability to comply with certain standards, and might be obliged to provide traceability of their conformity with outlined specifications.

\subsubsection{Black economic empowerment}

Black economic empowerment (BEE) aims to increase the participation of black people in all spheres of the South African economy [11]. BEE is seen in a negative light by the SME owner-managers. While three of the four SMEs comply with BEE, interviewee responses suggest that this organisationalstructural decision is unfavourable. SMEs simply adopt BEE to maintain business dealings with 
customers. The interviewees indicate that structuring through BEE guidelines is often unnecessary, placing undue financial burdens on the SME.

\subsubsection{Supply chain value net}

The importance of adopting a network perspective of the supply chain is demonstrated in understanding how the focal firm interacts with upstream and downstream entities. A prominent manifestation of this is collaboration. While all interviewees make reference to collaboration and its advantages, they have identified other interactions:

- Importing goods allows customers to act as competitors. Alternative material-sourcing increases fame, financial, and operational risks for the SME. Globalisation and the trend to procure cheap foreign goods essentially threatens the existence of SMMEs.

- $\quad$ Conversely, some SMEs use existing and potential competitors as suppliers. This lowers the risk for the focal firm in the short-term, but threatens all SMEs in the long run. This risk becomes more prominent as current international suppliers start operations in the South African market.

- The value net [4] allows the supply chain to see how not only suppliers, but also customers, can be focal firm complementors. SMEs can collaborate with upstream and downstream entities to service consumers or, alternatively, a further-downstream entity.

\subsection{Overlapping structural themes}

After scrutinising each data case, some responses were coded into two structural features. Further exploration of dual-grouped data segments revealed that they unavoidably overlap the structural facets of the framework. Three prominent issues were noted across the SMEs.

\subsubsection{Material resources}

While raw materials and components were originally included as part of logistics, they are also relevant to facilities. Material has implications for the type of resources that will be required for its processing: machinery, equipment, and plant layout. Due to the reference made to both facility and logistics, material resources must overlap with both dimensions.

\subsubsection{Human resources}

Employees of any company are the driving force behind production. The need for workers is significant, especially in businesses that do not have completely automated production. Workeers are a critical facility-related input. The data cases demonstrate that employer-employee relationships are pivotal in South African enterprises. Good relationships have allowed SMEs to have flexible work-scheduling. As discussed (in Section 2.3.2), logistics is the coordinating force in supply chains. This includes routing work teams and manufacturing processes. So human resources must be scrutinised under both facilities and logistics.

\subsubsection{Communication and information flow}

Logistics is considered to be the force that processes information through the supply chain. The need for information and communication both upstream and downstream of the supply chain is pivotal to managing risk for the focal firm considered. The need for customer and supplier relationships has been shown to contribute greatly to passing information on to the SME, with suppliers assisting the focal firm with market opportunities and alerting them to potential competition. Thus, communication and information overlap with logistics and relationships.

\subsection{The relationship between operational risk and strategic risk}

Strategic and operational risks appear to be intertwined. Strategic risks arise from decisions that affect the whole of a company, rather than just one or more areas [30], [31]. Strategic decisions may expose the company to greater risk in other dimensions, such as fame and financial. Conversely, operational risks stem from daily business. They relate to internal resources, processes, and systems. Although there is a marked difference between operational and strategic risks, it is unlikely that an organisation will achieve its strategic objectives without executing them as operational steps [32]. Simultaneously, operational objectives will not be supportive of each other or of the overall goals if they are not formed to achieve the organisation's strategy [32]. Thus operational and strategic risks are drivers of each other, and must be reconciled.

\subsection{Results}

The intra-case analysis was collated to present a final set of results. All dominant structural concerns were gathered to produce a final populated framework (refer to Figure 3). Shading was used to 


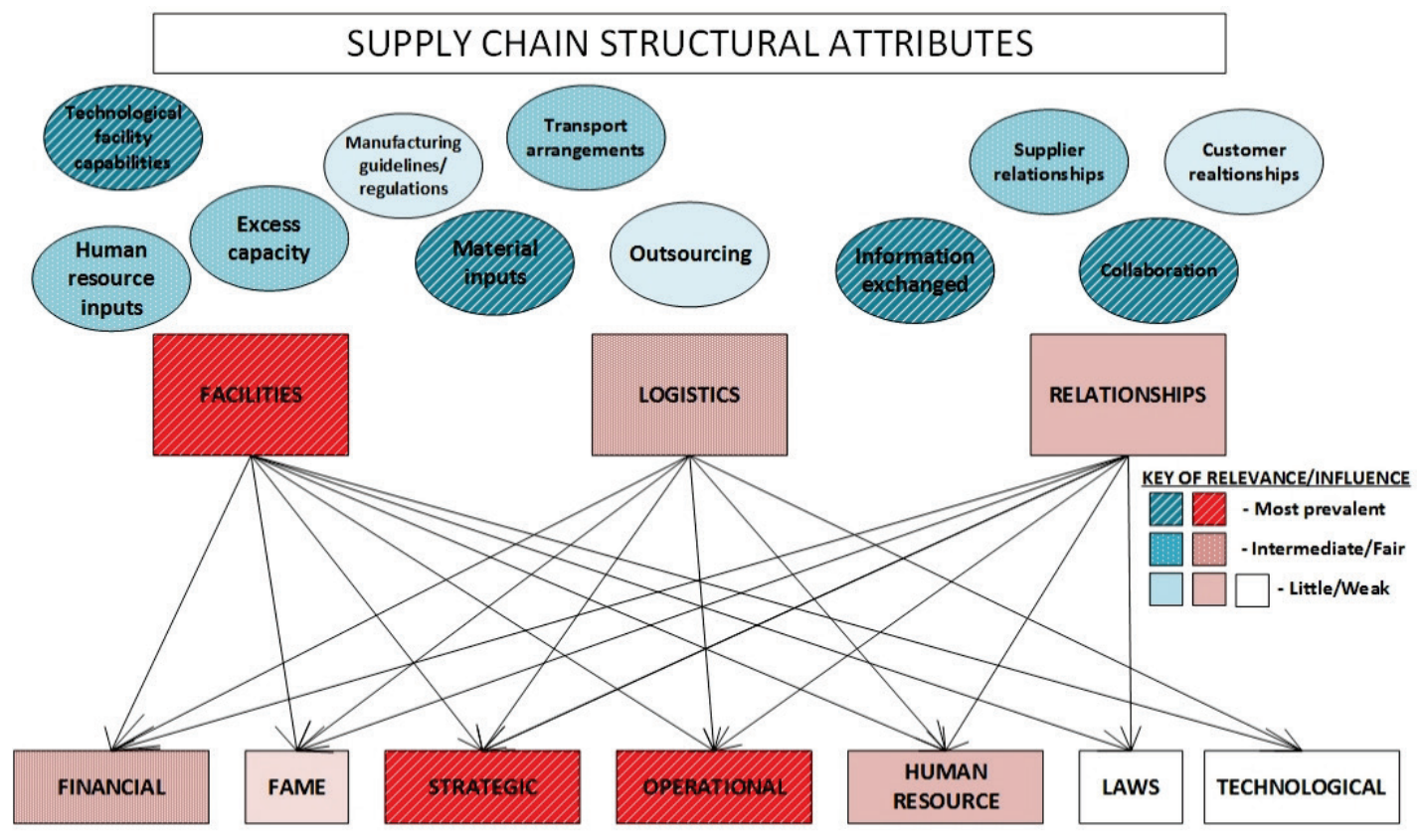

KEY SUPPLY CHAIN RISK DIMENSIONS

Figure 3: Populated framework of results

indicate the relevance of each dimension. Darker shading indicates higher significance, while fading intensity indicates less data-rich or harder-to-discern influences.

This research has illustrated that SCS does influence SCR. The analysis was interpretive, and the classification of SCS was largely based on the literature, at the discretion of the researcher. Based on the collated findings (Figure 3, Table 2), the hypotheses are evaluated in Table 3.

Table 2: Key structure-risk influences

\begin{tabular}{|c|c|c|}
\hline $\begin{array}{c}\text { Structure } \\
\text { aspect }\end{array}$ & Point/topic of discussion & Influence on risk dimension \\
\hline \multirow{4}{*}{ Facilities } & $\begin{array}{l}\text { Compliance with manufacturing } \\
\text { standards/guidelines }\end{array}$ & Increases operational risk \\
\hline & Infrastructure/equipment upgrades & $\begin{array}{l}\text { Lowers fame, financial risk; mixed effect on } \\
\text { operational and technological risk }\end{array}$ \\
\hline & $\begin{array}{l}\text { Close supplier proximity/ Having } \\
\text { local supply }\end{array}$ & Reduces operational, financial, fame, strategic risks \\
\hline & Worker availability in strike season & $\begin{array}{l}\text { Reduces operational, financial, reputation risks; } \\
\text { increases human resource risk }\end{array}$ \\
\hline \multirow{3}{*}{ Logistics } & Outsourcing of work & Transfers financial, operational, strategic risks \\
\hline & $\begin{array}{l}\text { Retaining raw material within the } \\
\text { defined supply chain }\end{array}$ & Mixed influence on reputation risk \\
\hline & $\begin{array}{l}\text { Maintaining customer } \\
\text { information/communication flow }\end{array}$ & Maintains operational, strategic risk \\
\hline \multirow{2}{*}{$\begin{array}{l}\text { Relation- } \\
\text { ships }\end{array}$} & Building supplier relationships & Reduces all risks, except technological \\
\hline & Collaboration in the SME & Reduces or transfers operational risk \\
\hline
\end{tabular}


Table 3: Evaluation of hypotheses

\begin{tabular}{|l|c|}
\hline \multicolumn{1}{|c|}{ Hypothesis } & $\begin{array}{c}\text { Accept/ } \\
\text { Reject }\end{array}$ \\
\hline $\begin{array}{l}\text { H1: The physical network structure (i.e., facilities and their attributes) will have direct } \\
\text { implications on all of the risk dimensions. }\end{array}$ & Accept \\
\hline H2: All SCS facets will have implications for an enterprise's supply chain strategy. & Accept \\
\hline H3: All SCS facets will have implications for an enterprise's supply chain operations. & Accept \\
\hline H4: SCS has a minimal influence on the human resource risk factor. & Reject \\
\hline
\end{tabular}

- The analysis of the study demonstrated that facilities directly influence all of the defined risk dimensions, with the exception of human resource risks. However, organisational and external factors impact human labour as a production resource in the manufacturing environment. Thus human resource risk is influenced indirectly by the facility structure.

- $\quad \mathrm{H} 2$ and $\mathrm{H} 3$ are supported through the emergent findings. SMEs adapt their business activities through changes in SCS. An example includes the decision to outsource changes in operational aspects, which results in changes of strategy. The converse relationship between operations and strategy is also true.

- $\quad$ H4 was rejected on the basis of human resource risk being evident in all three SCS dimensions. Human resource risk increases with the unavailability of productive labour during periods of protest action, while relationships in the organisation have a bearing on employee security.

\section{DISCUSSION}

Based on the sample SMMEs, the results of this exploratory research indicate that SCS does indeed influence SCR. The study further illuminates the relationships between certain dimensions of SCS, as well those existing between SCR classifications.

The provided cases show evidence that all three structure-dimensions influence SME risk. The most significantly-impacted risks include operational, strategic, financial, and fame. The results reveal that facilities exert strong but mixed influences on SCR. The reliance of SMEs on supplier relationships to manage risk was also demonstrated, with downstream (customer) relationships deemed to be important only in respect of information flow and reputation risk. Little was discerned of the effects of logistics in the supply chain; however, it has been considered to be significant in the light of operational and human resource risk management.

Facilities affect all seven risk dimensions of the framework, exerting strong but mixed influence on risk. Investment in new machinery and plant space might offer the ability to service new clients and meet greater demand, thus decreasing reputation risk. However, such investment poses a technological and operational threat if under-used. This has implications for all the SCR dimensions apart from human resources. Human resource risks appear to stem from (socio- political) macro factors rather than from SCS, and are somewhat beyond the SMEs' control. In the case of the SMEs studied, these occur in the form of strike action (see Section 2.2, 4.1.1). However, since these external factors have a bearing on labour as a resource, they indirectly influence SCR. Lastly, material unavailability as a facility input increases the operational risks.

A low level of information was recorded under logistics. This is owing to the initial framework design, which classifies raw material issues under facilities, and information flow as a relationships aspect. However, evidence indicates that SMEs use outsourcing to reduce their operational and financial risks. This concurs with Heizer and Render [3], who explain that outsourcing is often used to reduce costs for the focal firm. Not surprisingly, logistics is referred to in the context of coordination in the SME and the supply chain as a whole. Consequently, logistics should be a linking component in SCS.

The third feature of SCS - relationships - was easily analysed with discernable findings. It is crucial to grow and maintain supplier relationships, as they reduce the SME's operational and strategic risks. Conversely, customer relationships are not regarded as highly. Downstream relationships are a focal firm concern, due to the low level (or sometimes the absence) of information fed to the SME. However, customer relationships are valuable to the SME in planning production. This agrees with Matsoso and Benedict [25], who state that both upstream and downstream relationships must be enhanced to supply the end-consumer. The SME values supplier relationships, particularly in 
collaboration (see Table 2). Supplier collaboration is a key to the market survival of SMEs and to reducing strategic risk. Lastly, no evidence was collected to suggest that relationships (specifically information flow) impact technological risk. While the literature outlines the threats of online customer communication (refer to Section 2.3.3), the interviewees do not. This may be indicative of the naivety of the SME in implementing web-based commerce, or simply neglecting to discuss safety precautions in web design.

Of interest is the evident interaction between the various SCS features and risk classification. The interplay between strategic and operational risks often has a reinforcing effect on the SCR of the SME (refer to Section 4.3). Companies tend to describe the supply chain in terms of its supply-anddemand sides, and its effects on the 'bottom line' in both the short- and long-term. This emphasises the reconciliation between fame, financial, and strategic risks that is necessary to understand the firm's SCR. Increases in one of the finance dimensions appears to be a driver for change in an SME's strategy and operations, thus exerting an influence on strategic and operational risks.

This study, although limited to only four cases, supports the framework and the hypotheses on three of the four dimensions (in Table 3). Having illustrated that SCS influences SCR, it is important to consider the overlap of structural issues and feedback between structure and risk, and between risks. These links must be explored further fully to understand and rank the influences that SCS exerts on SCR.

\section{CONCLUSION AND RECOMMENDATIONS}

This exploratory study aimed to determine whether or not the SCS has an influence on SCR in South African SMMEs. This was achieved through the development of a structure-risk framework that facilitated the grouping of qualitative data about the structural features and the risks that they raise for the SME and the supply chain. Inferences about how the structure influences the various risk dimensions were also made.

- $\quad$ The research indicates that SCS does impact the SCR of South African SMMEs.

- The facility structure of the SME impacts all defined features of risk.

- $\quad$ Strong evidence suggests that outsourcing operations manage SMME risk.

- $\quad$ Supplier relationships are deemed more important overall than relationships with customers.

- Collaboration with suppliers, and sometimes customers, is a favourable way of reducing or transferring risk. It also increases the SMEs' resilience in the marketplace.

- Human resources are a pivotal influence on the risk of the South African SME, primarily in the form of labour unions and strike action.

- $\quad$ All facets of structure affect operational risk and strategic risk.

- Strategic and operational risks on the one hand, and financial and reputation risks on the other, are closely related and appear to reinforce each other. Consequently, these dimensions must be reconciled when evaluating SCR.

This attempt to determine the influence of SCS on SCR has highlighted both the value and the limitations of the conceptual framework. This exploration should be extended to a large number of SMMEs, using guided interviews. Results should also be tested against other risk and/or structure classifications to increase the validity and detail of the findings by way of framework differentiation.

\section{ACKNOWLEDGEMENTS}

This work is based on research supported in part by the National Research Foundation (NRF) of South Africa through Unique Grant No. 84397.

\section{REFERENCES}

[1] SME enterprise [Online]. Available: http://www.banking.org.za/what-we-do/inclusive-economy/sme/sme-enterprise. [Accessed 26 June 2015]

[2] Research Project Proposal 2015: Investigate and evaluate the supply chain structure of 4-5 manufacturing small and medium enterprises, Johannesburg: University of the Witwatersrand.

[3] Heizer, J. and Render, B. 2011. Principles of operations management, 8th ed., Pearson.

[4] Slack, N. and Lewis, M. 2011. Operations strategy, Prentice Hall. 
[5] Donald, C. and Waters, J. 2006. In Operations strategy, Cengage Learning EMEA, pp. 403-406.

[6] Meyr, H. and Stadtler, H. 2000. In Supply chain management and advanced planning: Concepts, models, software and case studies, 3rd ed., H. Stadtler and C. Kilger, eds., Berlin/Heidelberg/New York: Springer, pp. 69-71.

[7] Lambert, D.M., Cooper, M.C. and Pagh, J.D. 1998. Supply chain management: Implementation issues and research opportunities, International Journal of Logistics Management, 9(2), pp. 2-8.

[8] Smit, Y. and Watkins, J.A. 2012. A literature review of small and medium enterprises (SME) risk management practices in South Africa, African Journal of Business Management, 6(21), pp. 6324-6330.

[9] Harland, C.M., Caldwell, N.D., Powell, P. and Zheng, J. 2007. Barriers to supply chain information integration: SMEs adrift of Lands, Journal of Operations Management, 25, pp. 1234-1254.

[10] The 7 habits of highly successful SME supply chains, Finweek.com [Online]. Available: http://finweek.com/2014/06/27/entrepreneurship-7-habits-highly-successful-sme-supply-chains/. [Accessed 26 June 2015]

[11] Nieman, G. and Nieuwenhuizen, C. (eds). ntrepreneurship: A South African perspective, 2nd ed., Van Schaik Publishers, pp. 159-287.

[12] Dubihlela, J. 2014. Barriers to effective supply chain management, implementation, and impact on business performance of SMEs in South Africa, The Journal of Applied Business Research, 30(4), pp. 10191026.

[13] ZandHessami, H. and Savoji, A. 2011. Risk management in supply chain management, International Journal of Economics and Management Sciences, 1(3), pp. 60-72.

[14] Sunjka, B.P. and Sklar-Chik, M. 2012. Supply chain risk and small and medium manufacturing enterprises in South Africa, in CIE42 Proceedings, Cape Town.

[15] Chapman, C. Supply chain risk management: A comparative study of small to medium sized enterprises vs. large enterprises. Edwards School of Business, University of Saskatchewan.

[16] Sunjka, B.P. and Emwanu, B. 2013. A conceptual framework for the analysis of supply chain risk management in small and medium manufacturing enterprises in South Africa, in SAllE25 Proceedings, Stellenbosch.

[17] Zalk, N. 2014. What is the role of manufacturing in boosting economic growth and employment in South Africa? Econ 3x3 [Online]. Available: http: //www.econ3x3.org/article/ what-role-manufacturing-boostingeconomic-growth-and-employment-south-africa. [Accessed 11 July 2015]

[18] StatsSA. 2015. Manufacturing production flat in 2014. [Online]. Available: http://www.statssa.gov.za/?p=4064. [Accessed 11 July 2015]

[19] Joffe, H. 2015. Business: Cheap imports and poor policy hurting SA steel industry [Online]. Available: http://www.rdm.co.za/business/2015/04/23/cheap-imports-and-poor-policy-hurting-sa-steel-industry. [Accessed 11 July 2015]

[20] SEIFSA. 2015. Press releases [Online]. Available: http://www.seifsa.co.za/66-seifsa-news-press-releases2015/454-press-release-2015-06-17-high-electricity-price-increase-will-criplle-already-struggling-metalsand-engineering-sector.html. [Accessed 11 July 2015]

[21] President \& Fellows, Harvard University. 2008. Thematic analysis [Online]. Available: http://isites.harvard.edu/icb/icb.do?keyword=qualitative\&pageid=icb.page340897. [Accessed 20 July 2015]

[22] Clarke, V. and Braun, V. 2013. Teaching thematic analysis: Overcoming challenges and developing strategies for effective learning, The Psychologist, 26(2), pp. 120-123.

[23] Gono, S., Harindranath, G. and Özcan, G.B. Challenges of ICT adoption by South African SMEs. School of Management, Royal Holloway University of London, Surrey.

[24] Waters, D. (ed.) 2010. Global logistics: New directions in supply chain management, 6th ed., Kogan Page Limited.

[25] Forbes, C.S. 2012. Supply chain risk a hidden liability for many companies" [Online]. Available: http: //www. forbes.com/sites/steveculp/2012/10/08/supply-chain-risk-a-hidden-liability-for-manycompanies/. [Accessed 30 June 2015]

[26] Take control of your supply chains I supply chain management. 2015 [Online]. Available: http: //m.ltdmgmt.com/site/ltdmgmt/. [Accessed 6 May 2015]

[27] Hvolby, H.-H., Trienekens, J.H. and Carrie, A.S. Supply chain planning in small and medium sized enterprises, in Manufacturing Information Systems: Proceedings of The Fourth SMESME International Conference.

[28] Matsoso, M.L. and Benedict, O.H. 2014. The customer-supplier relationships in supply chain, Journal of Economics, 5(2), pp. 177-184.

[29] Finweek.com. 2015. SMEs under pressure to use tech more effectively [Online]. Available: http: / finweek.com/2015/04/01/business-smes-under-pressure-to-use-tech-more-effectively/. [Accessed 8 July 2015]

[30] Soko Directory. 2015. Factors affecting small and medium-sized enterprises [Online]. Available: http://sokodirectory.com/2015/05/factors-affecting-small-and-medium-sized-enterprises/. [Accessed 6 July 2015]

[31] The Banking Association South Africa. 2015. Small business definition [Online]. Available: http://www.banking.org.za/what-we-do/sme/sme-definition. [Accessed 13 August 2015]

[32] Student Accountant. 2008. Strategic and operational risks.

[33] Strategic risk vs operational risk. 2011 [Online]. Available: http://ampstuff.blogspot.com/2011/07/strategic-risk-vs-operational-risk.html. [Accessed 13 August 2015] 
[34] Petryni, M. Difference between strategic \& operational objectives. Demand Media [Online]. Available: http: //smallbusiness.chron.com/difference-between-strategic-operational-objectives-24572.html. [Accessed 13 August 2015]

[35] QSR International. What is qualitative research? Data analysis software [Online]. Available: http://www.qsrinternational.com/what-is-qualitative-research.aspx. [Accessed 3 August 2015]

[36] Maxwell, J.A. 2008. Designing a qualitative study, in The SAGE handbook of applied social reseach methods, SAGE Publications, pp. 214-249. 